\title{
Gengrafarests \\ A ECOFILOSOFIA NO PENSAMENTO DE HEIDEGGER E DE DELEUZE/GUATTARI
}

Revista do Programa de

Pós-Graduação em Geografia e do Departamento de Geografia da UFES

Julho-Dezembro, 2021

ISSN 2175-3709

\author{
EcoPhilosophy in the thought of Heidegger and Deleuze/Guattari \\ La EcoFilosofía en el pensamiento de Heidegger y Deleuze/Guattari \\ L'ÉcoPhilosophie dans la pensée de Heidegger et Deleuze/Guattari
}

\section{RESUMO}

O presente artigo foi escrito a partir de nossa pesquisa de PósDoutorado, cujo título é EcoFilosofia: Heidegger e Deleuzel Guattari - diálogo virtual, concluída em 2020. Nesta pesquisa, tentamos demonstrar a hipótese segundo a qual a EcoFilosofia é um conceito que subjaz tanto o pensamento de Martin Heidegger quanto o de Gilles Deleuze e de Félix Guattari. Isto significa que o conceito de EcoFilosofia é o impensado do pensamento de tais pensadores. Aqui, o impensado não significa o não pensado, mas o pensado, que, no entanto, não foi devidamente enunciado pelos mesmos. Donde por que a justificava maior desta pesquisa, a saber, enunciar o conceito de EcoFilosofia tal como foi pensado, de um lado, pelo pensador alemão, e, de outro, pela dupla de pensadores franceses. Mas, justamente, ao enunciar o conceito de EcoFilosofia no pensamento tanto de Heidegger quanto da dupla Deleuze e Guattari, também contribuímos para a sua criação - uma criação conceitual coletiva.

Palavras-chave: Filosofia; Metafísica; Ontologia; Ecologia; EcoFilosofia.

\section{A B STR A C T}

This article was written from our Post-Doctoral research, whose title is EcoPhilosophy: Heidegger and Deleuze/Guattari virtual dialogue, completed in 2020. In this research, we tried to demonstrate the hypothesis according to which EcoPhilosophy is a concept that underlies both the thinking of Martin Heidegger and that of Gilles Deleuze and Félix Guattari. This means that the concept of EcoPhilosophy is the unthinkable thought of such thinkers. Here, the unthought does not mean the no thought, but the thought, which, however, was not properly enunciated by them. Hence why this research was most justified, namely, to enunciate the concept of EcoPhilosophy as thought, on the one hand, by the German thinker, and, on the other, by the pair of French thinkers. But precisely by enunciating the concept of EcoPhilosophy in the thought of both Heidegger and the duo Deleuze and Guattari, we also contributed to its creation - a collective conceptual creation. 
KEYWORDS: Metaphysical; Philosophy; Ontology; Ecology; Ecophilosophy.

\section{RESUMEN}

Este artículo fue escrito a partir de nuestra investigación PostDoctoral, cuyo título es EcoFilosofia: Heidegger y Deleuze/ Guattari - diálogo virtual, completado en 2020. En esta investigación, intentamos demostrar la hipótesis según la cual la EcoFilosofía es un concepto que subyace tanto en el pensamiento de Martin Heidegger como en el de Gilles Deleuze y Félix Guattari. Esto significa que el concepto de EcoFilosofía es el pensamiento impensable de tales pensadores. Aquí, lo impensado no significa lo no pensado, sino el pensamiento, que, sin embargo, no fue debidamente enunciado por ellos. De ahí que esta investigación estuviera más justificada, a saber, para enunciar el concepto de EcoFilosofía como pensado, por un lado, por el pensador alemán, y, por otro, por la pareja de pensadores franceses. Pero precisamente al enunciar el concepto de EcoFilosofía en el pensamiento tanto de Heidegger como del dúo Deleuze y Guattari, también contribuimos a su creación, una creación conceptual colectiva.

Palabras-Clave: Filosofía; Metafísica; Ontología; Ecología; Ecofilosofía.

\section{RÉSUMÉ}

Cet article est issu de notre recherche Post-Doctorale, dont le titre est EcoPhilosophie: Heidegger et Deleuze/Guattari - dialogue virtuel, achevé en 2020. Dans cette recherche, nous avons tenté de démontrer l'hypothèse selon laquelle l'EcoPhilosophie est un concept qui sous-tend à la fois la pensée de Martin Heidegger et celle de Gilles Deleuze et Félix Guattari. Cela signifie que le concept d'ÉcoPhilosophie est l'impensable de la pensée de tels penseurs. Ici, l'impensé ne veut pas dire le non pensé, mais la pensée qui n'a pas été convenablement énoncée par ces philosophes. D'où la principale justification de notre recherche, à savoir, d'énoncer le concept d'ÉcoPhilosophie tel qu'il avait été pensé, d'une part, par le penseur allemand, et, d'autre part, par les deux penseurs français. Mais précisément en énonçant le concept d'EcoPhilosophie dans la pensée à la fois de Heidegger et du duo Deleuze et Guattari, nous avons également contribué à sa création - une création conceptuelle collective.

MOts-ClÉs: Philosophie; Métaphysique; Ontologie; Écologie; ÉcoPhilosophie.

\section{Gengrafaress}

Revista do Programa de Pós-Graduação em Geografia e do Departamento de Geografía da UFES

Julho-Dezembro, 2021 ISSN 2175-3709 


\section{Gengrafaress}

Revista do Programa de

Pós-Graduação em Geografia e do Departamento de Geografia da UFES

Julho-Dezembro, 2021

ISSN 2175-3709

\section{Em 2019, na Revista} Geografares, publicamos o artigo intitulado 0 ser do animal segundo Martin Heidegger, a partir de uma análise operada na primeira parte de nossa pesquisa de PósDoutorado, a saber, Martin Heidegger e a EcoFilosofia.

2. Nossa pesquisa de PósDoutorado EcoFilosofia: Heidegger e Deleuze/ Guattari - diálogo virtual deve-se ao financiamento e à estrutura do CNPq, da FAPES e da UFES, instituições sem as quais jamais realizaríamos nosso projeto.

3. Se, em Ser e tempo, Heidegger utiliza a expressão "ser-aí" (Dasein), em obras posteriores, tais como Os conceitos fundamentais da metafísica: mundo, finitude, solidão e Introdução à metafísica, ele próprio usa outras expressões para aludir à "estrutura" ontológica do homem, a exemplo de "ser-aí do homem" (Dasein vom Menschen) e "ser do homem" (Sein von Menschen), o que justifica nossa escolha terminológica para nomear umas das quatro partes do conceito maior de EcoFilosofia no pensamento de Heidegger.

\section{N T R O D U ÇÃ O}

O presente artigo foi escrito a partir de um convite feito por Cláudio Zanotelli, professor do curso de Geografia da UFES e editor da Revista Geografares, que acompanhou de perto o desenvolvimento de nossa pesquisa de Pós-Doutorado ${ }^{1}$, cujo título é EcoFilosofia: Heidegger e Deleuze/Guattari - diálogo virtual ${ }^{2}$ concluída em 2020. Nesta pesquisa, tentamos demonstrar a hipótese segundo a qual a EcoFilosofia é um conceito que subjaz tanto o pensamento de Martin Heidegger quanto o de Gilles Deleuze e de Félix Guattari. Isto significa que o conceito de EcoFilosofia é o impensado do pensamento de tais pensadores. Aqui, o impensado não significa o não pensado, mas o pensado, que, no entanto, não foi devidamente enunciado pelos mesmos. Donde por que a justificava maior desta pesquisa, a saber, enunciar o conceito de EcoFilosofia tal como foi pensado, de um lado, pelo pensador alemão, e, de outro, pela dupla de pensadores franceses. Mas, justamente, ao enunciar o conceito de EcoFilosofia no pensamento tanto de Heidegger quanto da dupla Deleuze e Guattari, também contribuímos para a sua criação - uma criação conceitual coletiva.

\section{O CONCEITO DE ECOFILOSOFIA, SEUS PRESSUPOSTOS E SEUS DESDOBRAMENTOS}

Todavia, tal como verificamos ao longo de nosso trabalho, o conceito de EcoFilosofia não é o mesmo no pensamento dos referidos filósofos. Grosso modo, podemos dizer que, em Heidegger, o conceito de EcoFilosofia é formado por quatro conceitos, qual seja, pelos conceitos 1. de "ser" do homem", 2. de "ser" do fabril, 3. de "ser" da natureza e 4. das relações entre os últimos, ao passo que, em Deleuze e Guattari, o conceito de EcoFilosofia é constituído por outros quatro conceitos, a saber, pelos conceitos 1. de "vir-a-ser" (devir) do homem, 2. de "vir-a-ser" (devir) do artifício, 3. de "vir-a-ser" (devir) da natureza e 4. das relações entre os mesmos. Ademais, tal como constatamos em nossa investigação, o conceito maior de EcoFilosofia desdobra-se em outros tantos conceitos ecofilosóficos, que diferem em cada um dos dois casos. No caso do pensador alemão, o conceito de EcoFilosofia desdobra-se em conceitos ecofilosóficos tais como estrutura-enquanto, privação, posse, ausência, acessibilidade, transposição, utilidade, serventia, prontidão, aptidão, pulsão, círculo da compulsividade-desinibição, órgãos, organismo, entre outros, que se circunscrevem à primeira fase de seu pensamento, a saber, a analítica existencial desde Ser e tempo até Introdução à metafísica, passando por Conceitos fundamentais da metafísica: mundo, finitude, 
solidão. Já no caso da dupla francesa, o conceito de EcoFilosofia desdobra-se em conceitos ecofilosóficos tais como máquinas desejantes, sínteses maquínicas, estrato, estratificação-desestratificação, Caos, terra/Terra, território, Cosmo, rizoma, ritornelo, platôs, agenciamento, linha de fuga, nomadismo, entre outros, que se delimitam ao projeto Capitalismo e esquizofrenia, que se inicia com $O$ anti-Édipo e se conclui com Mil Platôs, ainda que pressuponha certas obras anteriores, a exemplo de $D i$ ferença e repetição e Lógica do sentido, e implique outras obras posteriores, a exemplo de Kafka, por uma literatura menor, $O$ que é a Filosofia? e As três ecologias.

No entanto, se é possível falar do conceito de EcoFilosofia no pensamento tanto de Heidegger quanto de Deleuze e Guattari é porque, apesar das diferenças e mesmo em razão destas, há uma correspondência entre o conceito de EcoFilosofia em Heidegger e o conceito de EcoFilosofia em Deleuze e Guattari. Esta correspondência começa pelo mesmo tipo de análise, assim como pelos mesmos objetos analisados, a saber, uma análise de tipo ontológica sobre os fenômenos do homem, do fabril/artifício, da natureza e de suas relações. Em seguida, esta correspondência tem a ver com o mesmo tipo de montagem do conceito de EcoFilosofia, a saber, um conceito constituído por quatro partes, que não são senão outros conceitos, que aludimos acima. E, por fim, esta correspondência é relativa ao desdobramento em outros tantos conceitos ecofilosóficos, a partir do grande conceito de EcoFilosofia, que também mencionamos no parágrafo anterior. Portanto, no que tange estes três aspectos, o conceito de EcoFilosofia pensado tanto por Heidegger quanto por Deleuze e Guattari são correspondentes, razão pela qual é possível falar de uma EcoFilosofia conceitual em ambos os casos.

No entanto, esta correspondência possui um limite. É que, ao aprofundarmos nossa análise a respeito dos aspectos em comum do conceito de EcoFilosofia no pensamento de Heidegger e de Deleuze e Guattari, concluímos que o isomorfismo dá lugar ao heteromorfismo, tendo em visto que, se tanto Heidegger quanto Deleuze e Guattari operam uma análise ontológica sobre os fenômenos do homem, do fabril/artifício, da natureza e das relações entre os últimos, trata-se de análises ontológicas que partem de premissas distintas entre si: por um lado, a análise ontológica caracterizada pela analítica existencial em Heidegger, cujas premissas são os conceitos 1. de unidade, 2. de totalidade e 3 . de ipseidade ${ }^{4}$, e, por outro, a análise ontológica caracterizada pela Filosofia da Diferença e, como sucedâneo, pela Teoria da Multiplicidade em Deleuze e Guattari, cujas premissas
4. Na Filosofia, o conceito de ipseidade significa "ser si mesmo", motivo pelo qual, por um lado, pressupõe o conceito de identidade, tal como formulado por Aristóteles, a saber, $A=$ $A, e$, por outro, já implica o conceito de sujeito, tal como pensado por Descartes, qual seja, (Eu $=E U)$.

\section{gentrafaress}

Revista do Programa de Pós-Graduação em Geografia e do Departamento de Geografia da UFES

Julho-Dezembro, 2021 ISSN 2175-3709 


\section{Gengrafarest}

Revista do Programa de

Pós-Graduação em Geografia e do Departamento de Geografia da UFES

Julho-Dezembro, 2021 ISSN 2175-3709 são os conceitos 1 . de agenciamento, 2. de multiplicidade e 3 . de hecceidade; em seguida, se tanto Heidegger quanto Deleuze e Guattari montam o conceito de EcoFilosofia com quatro partes, que também são outros conceitos, trata-se conceitos diferentes entre si, qual seja, por um lado, o conceito de EcoFilosofia formado pelos conceitos 1. de "ser" do homem, 2. de "ser" do fabril, 3. de "ser" da natureza e 4. de relação entre os últimos em Heidegger, e, por outro, o conceito de EcoFilosofia constituído pelos conceitos 1 . de "vir-a-ser" (devir) do homem, 2. de "vir-a-ser" (devir) do artifício, 3. de "vir-a-ser" (devir) da natureza e 4. da relação entre os mesmos em Deleuze e Guattari, tal como mostramos preliminarmente; e, por fim, se tanto Heidegger quanto Deleuze e Guattari desdobram conceitos ecofilosóficos a partir do conceito maior de EcoFilosofia, trata-se de conceitos ecofilosóficos díspares entre si, tal como apresentamos previamente.

Mas, malgrado as referidas diferenças entre os dois conceitos de EcoFilosofia, ainda resta uma correspondência entre o pensamento de Heidegger e o de Deleuze e Guattari, qual seja, aquilo que ameaça o conceito de EcoFilosofia em ambos os casos: o conceito de Antropocentrismo Ontológico.

Segundo a teoria elaborada por Deleuze e Guattari, em todo pensamento filosófico, assim como há os conceitos positivos e atrativos, também há os conceitos negativos e repulsivos. Trata-se de conceitos que estabelecem um agon, uma luta, um combate entre si no campo aberto da Filosofia. Através deste agon filosófico, os conceitos repulsivos e negativos põem à prova os conceitos atraentes e positivos. Esta prova não é senão uma prova de insistência/persistência (força) e de permanência (de tempo enquanto duração) aplicada pelos conceitos repulsivos e negativos aos conceitos atraentes e positivos, cujo objetivo não é senão o de verificar a consistência (coesão entre suas partes baseada em força e duração) dos últimos. Neste agon filosófico, se os conceitos positivos e atrativos derrotam os conceitos negativos e repulsivos, provam sua consistência. Ao contrário, caso sejam derrotados, provam sua inconsistência, que não é propriamente um erro lógico nem tampouco um equívoco epistemológico, mas apenas e tão-somente uma ausência de consistência (coesão entre suas partes) pela falta de insistência/persistência (força) e de permanência (tempo enquanto duração). Neste sentido, os conceitos inconsistentes são os conceitos que não insistem/persistem (desistem) nem tampouco permanecem. Inversamente, os conceitos consistentes são os conceitos que justamente insistem/persistem e permanecem.

Todavia, não é possível afirmar que um conceito seja 
definitivamente consistente ou inconsistente em si mesmo. É que, através do agon conceitual, que é uma prova de força (insistência/persistência) e de tempo (permanência), todo conceito deve provar sua consistência em cada caso e a cada vez, isto é, deve provar sua consistência através de uma resistência (repetição). Isto significa que, ao resistir às diferentes circunstâncias ou situações (problemas), que, aliás, ultrapassam o próprio antagonismo do conceito negativo e repulsivo, um conceito positivo e atraente prova sua consistência. É por isto que não é possível saber se um conceito atraente e positivo é de fato consistente ou inconsistente a priori, isto é, antes de ser posto à prova da insistência/da persistência, da permanência e, finalmente, da resistência - respectivamente, à prova da força, do tempo e da repetição.

Eis por que, ao longo de nossa pesquisa, tentamos demonstrar a hipótese segundo a qual, no âmbito do pensamento tanto de Heidegger quanto de Deleuze e Guattari, o conceito de Antropocentrismo Ontológico (conceito repulsivo e negativo) põe à prova o conceito de EcoFilosofia (conceito atraente e positivo).

Tal como procuramos mostrar, no âmbito do pensamento de Heidegger, o conceito de Antropocentrismo Ontológico põe à prova o conceito de EcoFilosofia porque, segundo o tipo de análise ontológica caracterizada pela analítica fundamental, cujas premissas são os conceitos de unidade, de totalidade e de ipseidade, privilegia o conceito de "ser" do homem em detrimento do conceito de "ser" do fabril e de "ser" da natureza dentro das relações entre os referidos conceitos, que formam o conceito maior de EcoFilosofia. De fato, na perspectiva desta análise ontológica, este privilégio concedido ao conceito de "ser" do homem não seria um problema, caso não implicasse uma perda de potência ontológica relativamente ao conceito de "ser" do fabril e ao conceito de "ser" da natureza. Esta despotencialização ontológica (atrofia conceitual) dos conceitos de "ser" do fabril e de "ser" da natureza, que é encetada pela potencialização ontológica (hipertrofia conceitual) do conceito de "ser" do homem, testemunha a ação antagônica do conceito de Antropocentrismo Ontológico sobre o conceito de EcoFilosofia, antagonismo através do qual o primeiro revela a inconsistência do segundo. Eis por que a questão de fundo concerne às premissas da análise ontológica. A unidade, a totalidade e a ipseidade são as premissas a partir das quais Heidegger opera sua análise ontológica, através da qual produz seu conceito de EcoFilosofia, ao montá-lo com os conceitos 1. de "ser" do homem, 2. de "ser" do fabril, 3. de "ser" da natureza e 4. de suas relações, que tem a ver com sua analí-

\section{gengrafaress}

Revista do Programa de Pós-Graduação em Geografia e do Departamento de Geografia da UFES

Julho-Dezembro, 2021 ISSN 2175-3709 


\section{Gengrafaress}

Revista do Programa de

Pós-Graduação em Geografia e do Departamento de Geografia da UFES

Julho-Dezembro, 2021 ISSN 2175-3709 tica existencial. Na perspectiva da analítica existencial, é porque e somente porque o "Ser" enquanto tal caracteriza-se pela unidade, totalidade e ipseidade que, através do "ser" do homem, a percepção (nous) antecipada a cada vez opera a unificação, a totalização e a ipseização dos possíveis entes no futuro. E mais, é porque e somente porque a percepção (nous) antecipada a cada vez opera a unificação, a totalização e a ipseização dos possíveis entes no futuro que, através do "ser" do homem, a linguagem (logos) opera o transporte do ente enquanto tal na totalidade (mundo) através da transição temporal do futuro para o presente, de tal modo que o mundo é formado antecipadamente a cada vez. Isto significa que, embora o "ser" do fabril e o "ser da natureza não possuam uma existência nem tampouco um mundo próprio, o "ser" do homem empresta sua existência e seu mundo ao "ser" do fabril e ao "ser" da natureza, na medida em que, após operar a unificação, a totalização e a ipseização dos possíveis entes no futuro no âmbito da percepção (nous), opera o transporte do ente enquanto tal na totalidade (do mundo) através de sua transição temporal do futuro para o presente no âmbito da linguagem $(\log o s)$, que são os modos temporais que lhe pertencem. Pois, para Heidegger, é assim e somente assim que o "ser" dos entes ditos "fabris" e "naturais", a exemplo do "ser" do ente orgânico como o animal e/ou até mesmo do "ser" do ente inorgânico como a pedra, bem como de "ser" do ente inorgânico fabricado como o martelo, podem possuir uma existência e um mundo. Eis por que, por um lado, Heidegger monta o conceito de EcoFilosofia com os conceitos de "ser" do homem, de "ser" do fabril, de "ser" da natureza e de suas relações, mas, por outro, em razão mesmo desta montagem conceitual, que se baseia na análise ontológica caracterizada pela analítica existencial, cujas premissas são os conceitos de unidade, de totalidade e de ipseidade, privilegia o conceito de "ser" do homem em detrimento dos conceitos de "ser" do fabril, de "ser" da natureza e de suas relações. Mas, tal como quer Heidegger, a partir desta análise ontológica, que permite a montagem deste conceito de EcoFilosofia, se o conceito de "ser" do homem é privilegiado, trata-se de um privilégio concedido pelo próprio conceito de "Ser" enquanto tal, haja vista que, no âmbito conceitual, o último verte sua unidade, totalidade e ipseidade ao primeiro. Por isto, nesta análise ontológica, malgrado o modo impróprio de "ser" do "ser" do homem, que precariza a unificação, a totalização e a ipseização dos possíveis entes no futuro, assim como dificulta o transporte do ente enquanto tal na totalidade através da transição temporal do futuro para o presente, de 
tal modo que forma um mundo apenas parcial, o que acontece de início e na maior parte das vezes, no modo próprio de "ser" do "ser" do homem, este confunde-se com o próprio "Ser" enquanto tal. Donde por que, se Heidegger produz o conceito de EcoFilosofia, ao montá-lo com os conceitos de "ser" do homem, de "ser" do fabril, "ser" da natureza e de suas relações, o conceito de "ser" do homem ganha o status de sujeito ontológico. $\mathrm{O}$ conceito de sujeito ontológico atesta a potencialização ontológica (hipertrofia) do conceito de "ser" do homem, que, por sua vez, provoca a despotencialização ontológica (atrofia) dos conceitos tanto de "ser" fabril quanto de "ser" natureza - a nosso ver, em ambos os casos, uma desmedida (hybris) conceitual.

É bem verdade que a análise ontológica operada por Heidegger apresenta avanços teóricos significativos. Tais avanços têm a ver, por exemplo, com a crítica tecida por Heidegger aos conceitos de antropocentrismo e de logocentrismo vulgares, tais como criados pela tradição filosófica. Esta crítica mostra que não é a linguagem do homem que opera a unificação, a totalização e a ipseização dos entes no presente (crítica ao logocentrismo), criando o mundo de uma vez por todas (o "ser" simplesmente dado), o que se convencionou chamar de relação sujeito-objeto, mas a percepção (nous) antecipada a cada vez do "ser" do homem que, ao operar a unificação, a totalização e a ipseização dos possíveis entes no futuro, permite que a linguagem (logos) do "ser" do homem opere o transporte do ente enquanto tal na totalidade por meio da transição temporal do futuro para o presente, formando o mundo antecipadamente a cada vez. Outro exemplo dos referidos avanços teóricos consiste no fato de que Heidegger confere um status ontológico à natureza, ao reconhecer o "ser" da natureza, e antes, o "ser" de cada ente natural, tal como o "ser" da pedra e o "ser" do animal, que, por sua vez, distinguem-se entre si (o "ser" desta pedra, o "ser" deste animal"), bem como ao próprio fabril, ao reconhecer seu "ser" (o "ser" do martelo e/ou o "ser" deste martelo). Daí por que, por exemplo, ao analisar a temporalidade ontológica destes entes, reconhece a atemporalidade do "ser" da pedra versus a temporalidade ubíqua ou, se quisermos, a ubiqüidade temporal do "ser" do animal, e, ainda, a temporalidade específica do "ser" do fabril, tal como procuramos mostrar a partir de pistas deixadas por Heidegger. No entanto, o primeiro avanço teórico é bloqueado na medida em que, no âmbito conceitual, o sujeito ôntico é substituído pelo sujeito ontológico, tendo em vista que tanto a percepção (nous), que unifica, totaliza e ipseifica o "ser" dos entes a cada vez no futuro, quanto a lingua-

\section{gentrafaress}

Revista do Programa de Pós-Graduação em Geografia e do Departamento de Geografia da UFES

Julho-Dezembro, 2021 ISSN 2175-3709 


\section{Gengrafaress}

Revista do Programa de

Pós-Graduação em Geografia e do Departamento de Geografia da UFES

Julho-Dezembro, 2021 ISSN 2175-3709 gem (logos), que transporta o "ser" dos entes do futuro para o presente, ainda são atribuídas ao "ser" do homem, que, por isto mesmo, ganha o status de sujeito ontológico. Mas, no âmbito teórico, a partir do bloqueio do primeiro avanço, o segundo avanço também é bloqueado. É que Heidegger, conquanto reconheça o "ser" do fabril e o "ser" da natureza, bem como a especificidade ou a singularidade do "ser" de cada ente natural e fabril, ao afirmar a existência e o mundo enquanto fenômenos exclusivos do "ser" do homem, que, tal como mostramos, não é senão um sujeito ontológico, faz com que, de um lado, o "ser" do fabril e o "ser" da natureza tenham ou obtenham uma existência e um mundo (uma existência no mundo) apenas e tão-somente por empréstimo do "ser" do homem, e, de outro, em razão mesmo deste empréstimo, o "ser" de cada ente tanto fabril quanto natural perca sua própria singularidade ou diferença. É que o "ser" do homem, ao emprestar sua existência e seu mundo aos "seres" dos entes fabris e naturais, faz com que a singularidade ou diferença do "ser" de cada ente fabril e natural seja preterida em favor da identidade do "ser" do homem, ao menos em seu modo próprio.

Aqui, porém, não se trata do "ser" do homem enquanto o grau zero do "ser" do fabril nem da natureza. Para tanto, seria necessário que, de algum modo, o "ser" do homem anu- lasse o "ser" tanto do fabril quanto da natureza. Contudo, não se trata de uma anulação, mas de uma significação ou mesmo de uma ressignificação, visto que, através da percepção (nous) e da linguagem (logos) em seu sentido originário, o "ser" do homem cria sua existência e seu mundo por antecipação a cada vez. Disto resulta a despotencialização ontológica do conceito de natureza e do conceito de fabril, cujos "seres" são constantemente submetidos ao... e subsumidos pelo conceito de "ser" do homem enquanto sujeito ontológico. Pois é bem neste sentido que o conceito de EcoFilosofia, tal como pensado por Heidegger, cai na armadilha do conceito de Antropocentrismo Ontológico, do qual, a princípio, queria escapar, o que revela toda a sua inconsistência do ponto de vista conceitual.

Mas, tal como observamos, no âmbito do pensamento de Deleuze e Guattari circunscrito à obra $O$ anti-Édipo, o conceito de EcoFilosofia também é ameaçado pelo conceito de Antropocentrismo Ontológico, de tal modo que o segundo conceito põe a consistência do primeiro conceito à prova da insistência/persistência (força), da permanência (tempo) e da resistência (repetição). Nesta obra, ao operar sua análise ontológica, que se caracteriza pela Filosofia da Diferença e pela Teoria da Multiplicidade, cujas premissas são os conceitos de totalidade 
ao lado, de identidade indiciária da diferença e de sujeito residual, Deleuze e Guattari produzem seu próprio conceito de EcoFilosofia, ao montá-lo com os conceitos de "vir-a-ser" (devir) do homem, de "vir-a-ser" (devir) do artifício, de "vir-a-ser" (devir) da natureza e de suas relações. Tal como colocamos, enquanto premissas de sua análise ontológica, os conceitos de totalidade ao lado, de identidade indiciária da diferença e de sujeito residual apresentam certa ambiguidade. É que, por um lado, trata-se de conceitos que remetem à tradição filosófica, mas, por outro, testemunham uma ressignificação dos conceitos desta tradição.

No anti-Édipo, a princípio, é o caso do conceito de totalidade ao lado, que tanto remete ao conceito de totalidade enquanto conceito médio entre os conceitos de unidade e de ipseidade dentro da conhecida tríade metafísica (santa trindade), o que a Filosofia clássica atribuiu ao "Ser" e, partir desta atribuição, o próprio Heidegger estendeu ao "ser" do homem, de tal modo que o mesmo se transforma num sujeito ontológico, quanto testemunha sua ressignificação conceitual, tendo em visto que se trata de um novo conceito, o conceito de totalidade suplementar, um conceito de totalidade que não totaliza nada - uma espécie de totalização sem uma totalidade possível.

Em seguida, é o caso do conceito de identidade indi- ciária da diferença, que tanto remete ao conceito de identidade da Filosofia clássica, a exemplo do conhecido princípio de identidade $(\mathrm{A}=\mathrm{A})$, tal como formulado por Aristóteles e retomado por outros pensadores ao longo da história da Filosofia, de tal modo que se confunde com o conceito de unidade, que implica diretamente o conceito de totalidade e indiretamente do conceito de ipseidade (ser si mesmo) na tríade metafísica, e, por conseguinte, a longo prazo, fundamenta o conceito de sujeito $(E U=E U)$, quanto testemunha outra ressignificação conceitual, visto que também se trata de um novo conceito, o conceito de identidade não identitária, um conceito de identidade que não identifica nada, um conceito de identidade que, ao invés de identificar unitariamente, isto é, de unificar um fenômeno qualquer em sua suposta identidade, apenas indicia as diferenças deste fenômeno (nomes próprios, datas etc. na emergência de uma diferença).

E, finalmente, é o caso do conceito de sujeito residual, que tanto remete ao conceito de sujeito $(\mathrm{Eu}=\mathrm{Eu})$, sendo fundado e refundado por diversos pensadores ao longo da história da Filosofia, a exemplo de Descartes, Kant, Husserl etc., cujo fundamento é o conceito de identidade $(\mathrm{A}=\mathrm{A})$ com o qual se confunde o conceito de ipseidade enquanto o último dos conceitos da tríade metafísica, tal como elaborada

\section{gentrafaress}

Revista do Programa de Pós-Graduação em Geografia e do Departamento de Geografia da UFES

Julho-Dezembro, 2021 ISSN 2175-3709 


\section{Gengrafaress}

Revista do Programa de

Pós-Graduação em Geografia e do Departamento de Geografia da UFES

Julho-Dezembro, 2021 ISSN 2175-3709 pela Filosofia clássica, quanto testemunha uma terceira ressignificação conceitual, haja vista outro novo conceito, o conceito de sujeito que não sujeita, de tal modo que não estabelece a relação sujeito-objeto, mas apenas e tão-somente se sujeita à repetição da Diferença pura, que, do ponto de vista de um empirismo superior ou transcendental, não é senão a esquizofrenia enquanto um dos dois pólos do inconsciente (esquizofrenia-paranóia), razão pela qual o sujeito residual é o próprio esquizo.

Então, tal como procuramos mostrar, em $O$ anti-Édipo, os conceitos de identidade indiciária da diferença, de totalidade ao lado e de sujeito residual são as premissas da análise ontológica operada por Deleuze e Guattari, através da qual produzem seu conceito de EcoFilosofia, ao ser montado com os conceitos de "vir-a-ser" (devir) do homem, de "vir-a-ser" (devir) do artifício, de "vir-a-ser" (devir) da natureza e de suas relações. Ao ser posto à prova da insistência/ persistência (força), da permanência (tempo) e da resistência (repetição) pelo conceito de Antropocentrismo Ontológico, o conceito de EcoFilosofia prova sua consistência, na medida em que, através do trabalho de ressignificação dos conceitos de totalidade, de identidade e de sujeito, o conceito de "vir-a-ser" (devir) do homem não é privilegiado em detrimento dos conceitos de "vir-a-ser" (devir) do artifício e de "vir-a-ser" (devir) da natureza. No entanto, se tais conceitos apresentam certa ambiguidade é porque, através da relação antagônica entre o conceito de EcoFilosofia e o conceito de Antropocentrismo Ontológico, ainda que o primeiro predomine sobre o segundo, o segundo não é derrotado pelo primeiro. Com isto, o conceito de EcoFilosofia permanece sob a ameaça do conceito de Antropocentrismo Ontológico, ainda que tal ameaça de fato não se concretize. Em outras palavras, isto quer dizer que, conquanto o conceito de EcoFilosofia fuja à armadilha do conceito de Antropocentrismo Ontológico, absolutamente não a desarma, de tal modo que o primeiro permanece em perigo, o perigo de ser derrotado pelo segundo neste agon filosófico.

Por isto, para Deleuze e Guattari, é mister mudar as premissas de sua análise ontológica, através da qual fabricam o conceito de EcoFilosofia, ao montá-lo com os conceitos de "vir-a-ser" (devir) do homem, de "vir-a-ser" (devir) do artifício, de "vir-a-ser" (devir) da natureza e de suas relações. Não por acaso, em Mil Platôs, obra que, ao mesmo tempo, prolonga e conclui o projeto Capitalismo e esquizofrenia, cujo ponto de partida é a obra $O$ anti-Édipo, os conceitos de identidade indiciária da diferença, de totalidade ao lado e de sujeito residual são substituídos por 
novos conceitos, pelos conceitos de agenciamento, de multiplicidade, e de hecceidade, respectivamente. No entanto, esta substituição não significa um aperfeiçoamento conceitual. De fato, o conceito de multiplicidade não é um aperfeiçoamento do conceito de totalidade ao lado, assim como o conceito de agenciamento não é um aperfeiçoamento do conceito de identidade indiciária da diferença e, ainda, a conceito de hecceidade não é um aperfeiçoamento do conceito de sujeito residual. É que, conquanto os conceitos de totalidade ao lado, de identidade indiciária da diferença e de sujeito residual tenham provado sua consistência, também demonstraram sua insuficiência e mesmo uma deficiência para derrotar o conceito de Antropocentrismo Ontológico, cujas premissas são os conceitos de totalidade, de unidade e de ipseidade, que permaneceu como uma ameaça em relação ao referido conceito de EcoFilosofia. Por conseguinte, neste agon filosófico, que é também uma prova de força, de duração e de repetição, o conceito de EcoFilosofia requer não apenas uma consistência, mas também uma suficiência para, de fato, derrotar o conceito de Antropocentrismo Ontológico. Pois, justamente, ao escrever Mil Platos, Deleuze e Guattari obtêm esta suficiência, ao criar outras premissas, que não são senão novos conceitos ecofilosóficos, os conceitos de agenciamento, de multiplicidade e de hecceidade, que substituem os conceitos de identidade indiciária da diferença, de totalidade ao lado e de sujeito residual de $O$ anti-Édipo - conceitos que ainda guardavam certa filiação aos conceitos de unidade, totalidade e ipseidade enquanto premissas do conceito negativo e repulsivo de Antropocentrismo Ontológico.

Mas, tal como tentamos mostrar, para entendermos esta substituição, devemos nos ater ao conceito de multiplicidade, que, como conceito médio e intermediário, tanto pressupõe o conceito de agenciamento quanto implica o conceito de hecceidade. É que o conceito de multiplicidade contrapõe-se ao conceito de totalidade. Mas não apenas isto. Ao contrapor-se ao conceito de totalidade, o conceito de multiplicidade remete ao conceito de rizoma. Tal como mostramos, o conceito de rizoma estrutura o conceito de multiplicidade, mas também os conceitos de agenciamento e de hecceidade enquanto premissas da análise ontológica operada por Deleuze e Guattari, pela qual produzem seu conceito maior de EcoFilosofia, que é formada pelos conceitos de "vir-a-ser" (devir) do homem, de "vir-a-ser" (devir) da natureza, de "vir-a-ser" (devir) do artifício e das relações entre os mesmos. Com isto, os conceitos de agenciamento, de multiplicidade e de hecceidade ganham suficiente consistência ${ }^{5}$ não apenas para durar repeti-
5. Como qualquer outro conceito, o conceito de consistência, enquanto a primeira das três premissas da análise ontológica operada por Deleuze e Guattari, através da qual produzem seu conceito de EcoFilosofia, também deve provar sua consistência, sob pena de não ter duração nem permanência.

\section{gentrafaress}

Revista do Programa de Pós-Graduação em Geografia e do Departamento de Geografia da UFES

Julho-Dezembro, 2021 ISSN 2175-3709 


\section{Gengrafaress}

Revista do Programa de

Pós-Graduação em Geografia e do Departamento de Geografia da UFES

Julho-Dezembro, 2021 ISSN 2175-3709 damente com força, mas também para derrotar os conceitos de unidade, de totalidade e de ipseidade, que formam a tríade metafísica relativa à tradição filosófica sobre a qual se sustenta o conceito de Antropocentrismo Ontológico (sujeito ontológico). É que, a rigor, se o conceito de ipseidade depende do conceito de totalidade, assim como o conceito de totalidade depende do conceito de unidade, o último é um conceito inconsistente na medida em que sua consistência não se realiza nem se prova. Enquanto a primeira das três características atribuídas ao conceito de "Ser", o conceito de unidade pretende-se um conceito apodítico e a priori, isto é, um conceito auto-evidente e antecipado. Quando muito, no âmbito conceitual, invoca-se o suposto movimento de unificação através do qual se constitui a pretensa unidade enquanto condição de possibilidade da alegada totalidade e da presumida ipseidade, aliás, como quer o próprio Heidegger, ao analisar os modos de "ser" do "ser" do homem. Mas, mesmo neste caso, a unificação do conceito de "ser" do homem e, por conseguinte, do conceito de "ser" da natureza e de "ser" do fabril, que aponta para a formação do conceito de ente enquanto tal na totalidade, isto é, que acena para a formação do conceito de mundo, requer ainda o conceito de unidade enquanto primeira característica atribuída ao conceito de "Ser", que também se pretende um conceito auto-evidente (apodítico) e antecipado (a priori), e, consequentemente, inquestionado e mesmo inquestionável: "o "Ser" é (uno) e o não-". ser" não é (uno)", tal como já enunciava Parmênides. Mas, tal como mostramos em nossa Tese de Doutorado HomemTempo, mesmo quando Platão questiona o enunciado de Parmênides (o parricídio) através do Estrangeiro, ao enunciar que "o Ser é (uno) e o não-ser também é (uno)", trata-se ainda de um modo de legitimar o enunciado do pai Parmênides: "o Ser é (uno)". No entanto, ainda que Deleuze filie-se ao pensamento da univocidade do "Ser", a saber, "o Ser se diz de diferentes modos", no âmbito conceitual, ele e Guattari põem em questão esta suposta unidade originária atribuída ao "Ser". É que o conceito de unidade, ao condicionar diretamente o conceito de totalidade e indiretamente o conceito de ipseidade (ser si mesmo), exclui o conceito de diferença, de "vir-a-ser", de devir. É bem neste sentido que a unidade é a primeira das premissas da análise ontológica através da qual Heidegger produz seu conceito de EcoFilosofia, ao montá-lo com os conceitos de "ser" do homem, de "ser" do fabril, de "ser" da natureza e de suas relações, que, no entanto, revela-se como um conceito inconsistente, na proporção em que o conceito de "ser" do homem é privilegiado em detrimento dos conceitos de "ser" 
do fabril e de "ser" da natureza, de tal modo que ganha o status de sujeito ontológico, testemunhando o predomínio, a supremacia, a primazia do conceito de Antropocentrismo Ontológico sobre o conceito de EcoFilosofia. Mas, igualmente, é bem neste sentido que Deleuze e Guattari questionam o conceito de unidade, ao criar e propor um novo conceito, o conceito de agenciamento, um conceito que inclui aquilo que o conceito de unidade exclui, qual seja, a diferença em ato, o "vir-a-ser", o devir. Mas se o conceito de agenciamento é um conceito consistente é não apenas porque inclui o conceito de diferença em ato, de "vir-a-ser", de devir, mas também porque, diferente do conceito de unidade, que se pretende um conceito auto-evidente (apodítico) e antecipado (a priori), mostra seu modus operandi através de outro conceito, a saber, o conceito de contração. Aqui, o conceito de contração deve ser entendido no sentido literal de contra-ação. O conceito de contração é contrário ao conceito de ação, assim como é favorável ao conceito de paixão: não age, mas padece. Contrair é o mesmo que padecer porque, no conceito de contração, sofre-se uma ação, mas de tal modo que a ação sofrida dure, permaneça, conserve-se, o que aponta para a consistência do conceito de diferença em ato, de "vir-a-ser", de devir. Porém, diferente do conceito de unidade, que é atribuído ao conceito de "Ser" enquanto um conceito auto-evidente e antecipado (conceito de unidade enquanto conceito apodítico e a priori), o conceito de agenciamento, em razão do conceito de contração enquanto seu modus operandi, que o caracteriza e o esclarece, alude ao conceito de diferença em ato, de "vir-a-ser", de devir, cuja consistência deve ser provada, demonstrada, testada em cada caso e a cada vez. Eis por que, na análise ontológica operada por Deleuze e Guattari, através da qual se produz o conceito de EcoFilosofia, ao montá-lo com os conceitos de "vir-a-ser" (devir) do homem, de "vir-a-ser" (devir) do artifício, de "vir-a-ser" (devir) da natureza e de suas relações, cujas premissas são os conceitos de agenciamento, de multiplicidade e de hecceidade, o conceito de agenciamento é determinado pelo conceito de contração, que se constitui como seu modus operandi - o agenciamento agencia as multiplicidades ao contraí-las em cada caso e a cada vez. Com isto, o conceito de agenciamento derrota o conceito de unidade, já prenunciando a vitória do próprio conceito de EcoFilosofia sobre o conceito de Antropocentrismo Ontológico.

Mas, em Mil Platôs, se o conceito de agenciamento derrota o conceito de unidade, o que não havia acontecido na batalha travada entre o conceito de identidade indiciária da diferença e o conceito de unidade em $O$ anti-Édipo, isto não implica antecipadamente

\section{gentrafaress}

Revista do Programa de Pós-Graduação em Geografia e do Departamento de Geografia da UFES

Julho-Dezembro, 2021 ISSN 2175-3709 


\section{gengrafaress}

Revista do Programa de

Pós-Graduação em Geografia e do Departamento de Geografia da UFES

Julho-Dezembro, 2021 ISSN 2175-3709 a vitória do conceito de EcoFilosofia sobre o conceito de Antropocentrismo Ontológico. Nenhuma batalha é vencida ou perdida por antecipação. $\mathrm{Na}$ verdade, para tanto, faz-se necessário travar outras duas batalhas conceituais no âmbito de Mil Platôs: o conceito de multiplicidade versus o conceito de totalidade e o conceito de hecceidade versus o conceito ipseidade, tendo em vista que, em $O$ anti-Édipo, as batalhas travadas entre o conceito totalidade ao lado versus o conceito de totalidade e o conceito de sujeito residual versus o conceito de ipseidade permaneceram praticamente empatadas, ainda que os primeiros tenham predominado sobre os segundos.

$\mathrm{Na}$ segunda batalha, o conceito de multiplicidade apresenta uma consistência porque é determinado pelo conceito de contágio enquanto seu modus operandi, visto que, no âmbito conceitual, as multiplicidades formam-se, produzem-se e proliferam-se através do contágio entre fenômenos, corpos, indivíduos de diferentes naturezas e graus, que são outras tantas multiplicidades, ao passo que o conceito de totalidade não apresenta consistência alguma porque, a exemplo do conceito de unidade, é outro conceito que se quer auto-evidente (apodítico) e antecipado (a priori), embora tal querer não se realize nem tampouco se demonstre. É que o conceito de totalidade, em razão de sua suposta auto-evi- dência (apoditismo) e antecipação (apriorismo), se escusa de provar sua consistência, enquanto o conceito de multiplicidade, em virtude mesmo do conceito de contágio enquanto seu modus operandi, que o determina, deve provar sua consistência em cada caso e a cada vez. Ademais, mesmo se considerarmos o conceito de totalização enquanto modus operandi através do qual se determina o conceito de totalidade, ainda se trata de um conceito inconsistente, visto que, tal como nos ensina Bergson, o conceito de totalidade apresenta um erro lógico, afinal, ao contemplar o suposto fenômeno da totalidade, seu respectivo conceito fica sempre e necessariamente de fora. Eis por que o conceito de totalidade apresenta-se como uma dimensão suplementar em relação ao suposto fenômeno da totalidade $(\mathrm{n}+1)$, o que aponta não para uma totalidade, mas para uma parcialidade - uma contradição em termos. Com isto, nesta segunda batalha, o conceito de multiplicidade também derrota o conceito de totalidade.

Mas ainda resta a terceira e última batalha, a batalha na qual o conceito de hecceidade também demonstra uma consistência porque é determinado pelo conceito de individuação enquanto seu modus operandi, haja vista que, no âmbito conceitual, o outro individua-se, sem, no entanto, tornar-se o mesmo, isto é, a diferença em ato, o "vir-a-ser", 
o devir torna-se um indivíduo, embora não seja uma indivíduo ao modo do sujeito nem tampouco do objeto, ao mesmo tempo em que o conceito de ipseidade não demonstra qualquer consistência porque, a exemplo dos conceitos de unidade e de totalidade, é outro conceito que se pretende auto-evidente (apodítico) e antecipado (a priori). Deste modo, o conceito de ipseidade, em virtude de sua pretensa auto-evidência (apoditismo) e antecipação (apriorismo), também se isenta de demonstrar sua consistência, ao passo que o conceito da hecceidade, em razão do conceito de individuação enquanto seu modus operandi, que o determina, deve demonstrar sua consistência em cada caso e a cada vez. De mais a mais, mesmo considerando o conceito de ipseização enquanto modus operandi pelo qual se determina o conceito de ipseidade, trata-se ainda de um conceito inconsistente, dado que, a rigor, o sentido do conceito de ipseidade enquanto "ser si mesmo" jamais se cumpre. Não por acaso, no âmbito conceitual, ao tratar da formação do ente enquanto tal na totalidade, isto é, da formação de mundo, mesmo Heidegger não se refere à ipseização operada pela percepção (nous) antecipada a cada vez dos possíveis entes no futuro, ainda que a pressuponha, ao lado da unificação e da totalização. É que, tal como ele entende, tanto o "ser" do fabril quanto o "ser" da natureza somente podem "ser si mesmo" para o "ser" do homem ("ser-para" enquanto destinação). Eis por que, em Mil platôs, assim como os conceitos de agenciamento e de multiplicidade derrotam, respectivamente, os conceitos de unidade e de totalidade, o conceito hecceidade também derrota o conceito de ipseidade nesta terceira e última batalha.

Mas se, por um lado, na análise ontológica operada por Heidegger, o conceito de Antropocentrismo Ontológico predomina sobre o conceito de EcoFilosofia em razão dos conceitos de unidade, de totalidade e de ipseidade, premissas que se provam inconsistentes; se, por outro, na análise ontológica operada por Deleuze e Guattari, os conceitos de agenciamento, de multiplicidade e de hecceidade derrotam os conceitos de unidade, de totalidade e de ipseidade, premissas que se provam consistentes; o corolário não pode ser outro a não ser o de que, neste último caso, o conceito de EcoFilosofia derrota o próprio conceito de Antropocentrismo Ontológico dentro deste agon conceitual travado em Mil Platôs. Somente sob esta condição, sob a condição de criar um conceito de EcoFilosofia consistente, que Guattari poderá pensar, por exemplo, as três ecologias enquanto três novos conceitos, que justamente dão nome à sua obra, de 1989, a saber, a ecologia ambiental, a ecologia social

\section{gentrafaress}

Revista do Programa de Pós-Graduação em Geografia e do Departamento de Geografia da UFES

Julho-Dezembro, 2021 ISSN 2175-3709 


\section{Gengrafaress}

Revista do Programa de

Pós-Graduação em Geografia e do Departamento de Geografia da UFES

Julho-Dezembro, 2021

ISSN 2175-3709 ou coletiva e a ecologia individual, assim como a ecosofia enquanto um novo saber, que envolve uma ética, uma estética e uma política, relativo às últimas.

Uma ecosofia de um tipo novo, ao mes-
mo tempo prática e especulativa, ético-
-política e estética, deve a meu ver subs-
tituir as antigas formas de engajamento
religioso, político, associativo (...) Con-
cluindo, as três ecologias deveriam ser
concebidas como sendo da alçada de
uma disciplina comum ético-estética e,
ao mesmo tempo, como distintas uma das
outras do ponto de vista das práticas que
as caracterizam. Seus registros são da al-
çada do que chamei heterogenese, isto é,
processo contínuo de ressingularização.
Os indivíduos devem se tornar a um só
tempo solidários e cada vez mais diferen-
tes. (GUATTARI, 1990, p. 54 e 55).

Mas é sob a mesma condição, sob a condição de criar um conceito de EcoFilosofia consistente, que Deleuze e Guattari poderão escrever do Caos ao cérebro, último capítulo da obra $O$ que é a Filosofia?, de 1992. Trata-se de um capítulo ecofilosófico porque testemunha a criação de conceitos ecofilosóficos enquanto desdobramentos do grande conceito de EcoFilosofia, que, no entanto, permanece subjacente ao pensamento da dupla francesa. E mais, trata-se de um capítulo no qual Deleuze e Guattari despedem-se do conceito de EcoFilosofia, ao criar conceitos ecofilosóficos pela última vez. Não há dúvida de que é uma despedida em grande estilo, tendo em vista a envergadura dos conceitos ecofilosóficos criados e/ou mesmo recriados, tais como os de Caos, de cérebro, de contração, de vitalismo, entre outros, que apareceram e/ou reapareceram em obras anteriores, mas que, em $O$ que é a filosofia?, em razão mesmo do sentido desta obra, que é expresso em seu próprio título, qual seja, esclarecer, do ponto de vista tanto especulativo quanto prático, o que é a Filosofia enquanto aquilo que ambos realizaram ao longo da vida, ganham uma clareza e uma precisão ainda maiores.

O conceito ecofilosófico de cérebro é o conceito que contempla o fenômeno do recorte do Caos em planos, a saber, o plano de imanência da Filosofia, o plano de composição da Arte e, finalmente, o plano de referência ou de coordenação da Ciência. Deleuze e Guattari chamam de Caióde cada um destes saberes, que é a realidade produzida em cada um destes planos. Cada um destes planos, com seu respectivo saber ou realidade, constitui-se como um modo de fugir ao Caos, mas também como um modo de extrair uma pequena quantidade de Caos para lhe imprimir uma determinada ordem sem a qual a não é possível a própria vida. Ao que chegamos ao segundo conceito ecofilosófico: a contração. A contração constitui-se como o modo através do qual, em cada plano com seu respectivo saber, ordena-se essa porção caótica, que, sempre e necessariamente, deve ser extraída do próprio Caos em cada caso, a cada vez e para cada fim. Se o Caos é constituído por relações de força erráticas, disparatadas, loucas, entre partículas intensivas, o que aponta 
para um "devir-louco", o ordenamento das porções de Caos consiste em ordenar as relações de força, de tal modo que as partículas intensivas sejam contraídas, estabelecendo um continuum, uma permanência, uma duração da própria Diferença pura, o que acena para outros tipos de devir. Pois, sob a inspiração de Platão, Plotino, Agostinho, Hume e Bergson, para citar apenas os mais relevantes, Deleuze e Guattari pensam o conceito de duração da Diferença pura através do conceito de consistência, com a qual se confunde o conceito de platô, que, tal como vimos, não apenas compõe uma Multiplicidade, mas também, em si mesmo, é outra Multiplicidade. Pois, para a dupla de pensadores franceses, o maior dos problemas é o seguinte: como dar consistência às multiplicidades em permanentes agenciamentos (desestratificações relativas e/ou absolutas) no plano de imanência, isto é, como fazer com que as multiplicidades insistam/persistam, permaneçam e resistam às mais diferentes circunstâncias e aos mais distintos perigos (problemas), a exemplo das estratificações e/ou reestratificações e, sobretudo, da linha de morte ou abolição? Neste sentido, o conceito ecofilosófico de contração conduz ao conceito ecofilosófico de vitalismo superior, que, para Deleuze e Guattari, não deve ser confundido com o conceito de vitalismo inferior ou ingênuo. É que, para eles, o conceito de vitalismo inferior ou ingênuo refere-se à ação, ao mesmo tempo, biológica e cognitiva, a saber, as ações enquanto "conexões nervosas excitação-reação" (horizontais), que abarcam a percepção, assim como as ações enquanto integrações sinápticas (verticais), que envolvem o cérebro - ambas as ações do ponto de vista da Gestalttheorie. Neste sentido, o vitalismo inferior ou ingênuo apenas aparentemente se contrapõe ao mecanicismo, visto que, se este limita-se ao ato reflexo ou reflexo condicionado produzido pelo córtex, se aquele circunscreve-se às conexões e às integrações produzidas, respectivamente, pela percepção e pelo cérebro, tanto o mecanicismo quanto o vitalismo inferior ou ingênuo atém-se às mesmas ações predeterminadas (repetição do mesmo), ainda que as ações do último sejam mais complexas. Eis por que, em última instância, as mesmas ações predeterminadas, seja no âmbito da percepção e do cérebro, seja no âmbito do córtex, são a base sobre a qual se constituem o clichê na Arte, o teorema na Ciência, a opinião ou doxa na Filosofia, mas também da urdoxa na Filosofia ao modo da Fenomenologia, que, se ultrapassa o vitalismo inferior ou ingênuo, ultrapassa-o para reencontrá-lo mais adiante, ao conceber um sujeito ontológico, que se confunde com o próprio "Ser" enquanto tal, como predeterminação do sujeito, do mundo e da ligação

\section{gentrafaress}

Revista do Programa de Pós-Graduação em Geografia e do Departamento de Geografia da UFES

Julho-Dezembro, 2021 ISSN 2175-370S 


\section{Gengrafaress}

Revista do Programa de Pós-Graduação em Geografia e do Departamento de Geografia da UFES

Julho-Dezembro, 2021 ISSN 2175-3709 entre ambos no âmbito ôntico. Mas, tal como pontuam Deleuze e Guattari, não nos cabe apenas contestar as explicações do vitalismo inferior ou ingênuo e do mecanicismo, mas também explicar aquilo que eles não explicam. E eis que a dupla de pensadores franceses chega ao conceito ecofilosófico de vitalismo superior. Diferente do vitalismo inferior e ingênuo, que, apesar da aparente contraposição, vai ao encontro do mecanicismo em razão da ação predeterminada (predeterminação), cujo fim é a reprodução do velho (repetição do mesmo), o vitalismo superior vai ao encontro do maquinismo em virtude da contração indeterminação, cujo meio é a produção do novo (Repetição da Diferença pura), tal como constatamos em um dos capítulos de nossa pesquisa de Pós-Doutorado dedicado à obra $O$ anti-Édipo. É que se o vitalismo inferior ou ingênuo refere-se à ação enquanto conexões perceptivas e integrações cerebrais, o vitalismo superior alude à contração afectiva, que, tal como colocamos acima, deve ser entendido em seu sentido literal, isto é, como uma contra-ação e, por conseguinte, como uma paixão relativa à percepção e, sobretudo, ao cérebro. Eis por que, sob a inspiração do filósofo Alfred Whitehead, Deleuze e Guattari entendem o cérebro menos como agente com suas integrações sinápticas do que como paciente com suas contrações afectivas. Os afectos caracterizam as relações de força entre partículas intensivas (matéria pura), que, uma vez contraídas, constituem as cadeias, as séries, os processos heterogêneos, isto é, os devires, que, do ponto de vista ontológico, apontam para a consistência da Diferença pura em ato, ou melhor, em contra-ação. Então, isto quer dizer que somente os seres vivos dotados de cérebro e de sistema nervoso central são capazes de contrair e, consequentemente, de diferenciar-se de maneira consistente? Não. Se Deleuze e Guattari filiam-se ao vitalismo, que ora definimos como vitalismo superior, é porque entendem que o cérebro, ou antes, os microcérebros espraiam-se por todo Universo, o que inclui os seres orgânicos aparentemente "descerebrados", a exemplo da planta, os seres inorgânicos, a exemplo da pedra, e, ainda, os seres inorgânicos artificiais, a exemplo das máquinas em seu sentido mais amplo.

\footnotetext{
As rochas e as plantas certamente não têm sistema nervoso. Mas, se as conexões nervosas e as integrações cerebrais supõem uma força-cérebro como faculdade de sentir coexis-tente aos tecidos, é verossímil supor também uma faculdade de sentir que coexiste com os tecidos embrionários, e que se apresenta na Espécie como cérebro coletivo; ou com os tecidos vegetais nas "pequenas espécies". Não só as afinidades químicas, como as causalidades físicas remetem elas mesmas a forças primárias capazes de conservar suas longas cadeias, contraindo os elementos e fazendo-os ressoar: a menor causalidade permanece ininteligível sem esta instância subjetiva. Nem todo organismo é cerebrado, e nem toda vida é orgânica, mas há em toda a parte forças que constituem microcérebros, ou uma vida inorgânica das coisas. Se não é indispensável fazer a esplêndida hipótese de um sistema nervoso da Terra, como Fechner ou Conan Doyle, é porque a força de con-
} 
trair ou de conservar, isto é, de sentir, só se apresenta como um cérebro global em relação a tais elementos diretamente contraídos e a tal modo de contração, que diferem segundo os domínios e constituem precisamente variedades irredutíveis. Mas, no final das contas, são os mesmos elementos últimos e a mesma força de reserva que constituem um só plano de composição, suportando as variedades do Universo. (DELEUZE; GUATTARI, 1997, p. 272 e 273).

Mas, ao afirmar que "nem todo organismo é cerebrado, e nem toda vida é orgânica, pois há em toda a parte forças que constituem microcérebros, ou uma vida inorgânica das coisas", Deleuze e Guattari não apenas criam o conceito ecofilosófico de vitalismo superior, mas também estabelecem um vínculo entre o último e o conceito de animismo metafísico, tal como Deleuze investigou em Diferença e repetição, ao abordar a teoria das mônadas ou das "pequenas almas", segundo Leibniz: os microcérebros estão para o vitalismo superior, assim como as pequenas almas estão para o animismo metafísico. Por isto, Claudio Ulpiano tem razão ao dizer que (...)

(...) Assim, Deleuze seria como que um momento dessa tradição de pensamento que teria emergência em Plotino e que segue errante e triunfalmente pelos mais brilhantes pensadores da Humanidade. Eis quando Deleuze liga, de uma maneira notável, o animismo à biologia molecular, mostrando que todas as grandes conquistas que a biologia teria feito nesse século seriam fundamentadas na força do animismo, o que leva os biólogos a exercerem um pensamento totalmente original como se fosse um prolongamento do Erehwon, do trabalho de Samuel Butler; sua semente contemplativa encarnando-se na biologia molecular poderosa. Alma, então, como a semente da rosa: somente focos de percepção e de afecção moleculares, contemplações, microcontemplações. Os corpos todos, quaisquer, nenhum em exceção, são povoados de pequenas almas, de mônadas. As mônadas: a idéia monadológica soberba, a espiritualização do real. E a verdade, então, será a força que não age mas que percebe e experimenta. (ULPIANO, 1995).

Mas, curiosamente, ao final da obra $O$ que é a Filosofia?, Deleuze e Guattari retomam o conceito de sujeito. É que, para eles, a exemplo das mônadas ou das pequenas almas em Leibniz, os microcérebros também são sujeitos, mas são sujeitos apenas e tão-somente porque se sujeitam, padecem, sofrem a contração através da qual se produz o novo de modo indeterminado. Portanto, aqui, absolutamente não se trata do sujeito ontológico com o qual o esquizo ainda corria o risco de confundir-se em $O$ anti-Édipo. Tanto é assim que, para eles, "é o cérebro que pensa e não o homem, o homem sendo apenas uma cristalização cerebral" (DELEUZE; GUATTARI, 1992, p. 267).

Pois é bem neste sentido que o conceito ecofilosófico de vitalismo (superior) remete a outro conceito, que é igualmente ecofilosófico: o conceito de anti-humanismo. Se Deleuze e Guattari ainda podem falar do cérebro ou dos microcérebros enquanto sujeitos é nesta perspectiva aberta pelo conceito ecofilosófico de anti-humanismo, que se contrapõe ao conceito de sujeito ôntico (o homem), mas também e sobretudo ao conceito de sujeito ontológico, ao sujeito que, indevidamente, ocupa o centro da ontologia, ao sujeito do antropocentrismo ontológico com o qual se confunde o próprio "ser”(-aí) do homem (Dasein), tal como

\section{gengrafaress}

Revista do Programa de Pós-Graduação em Geografia e do Departamento de Geografia da UFES

Julho-Dezembro, 2021 ISSN 2175-3709 


\section{Gengrafaress}

Revista do Programa de

Pós-Graduação em Geografia e do Departamento de Geografia da UFES

Julho-Dezembro, 2021 ISSN 2175-3709 pensado por Heidegger, de tal modo que, não por coincidência, numa clara alusão ao pensador alemão, a dupla de pensadores franceses pergunta se a "viragem não estaria em outra parte, lá onde o cérebro (...) se torna sujeito?" (DELEUZE; GUATTARI, 1992, p 269).

Em outras palavras, isto quer dizer que Deleuze e Guattari, ao operar a análise ontológica, cujas premissas são os conceitos de consistência, de multiplicidade e de hecceidade, através da qual produzem o conceito de EcoFilosofia, que é montado através dos conceitos de "vir-a-ser" do (devir) homem, de "vir-a-ser" (devir) do artifício, de "vir-a-ser" (devir) da natureza e de suas relações, não potencializam o primeiro termo em detrimento dos demais. Bem ao contrário, tal como observamos ao final da segunda parte de nossa pesquisa de Pós-Doutorado, eles potencializam os conceitos de "vir-a-ser" (devir) do artifício e de "vir-a-ser" (devir) da natureza, tendo em vista que, no âmbito conceitual, se a liberdade do homem exige seu "vir-a-ser" (devir), o "vir-a-ser" (devir) do homem requer tanto o "vir-a-ser" (devir) do artifício quanto o "vir-a-ser" (devir) da natureza, sem os quais ele não pode ser livre. Eis por que a liberdade do homem consiste nos devires, que, antes de tudo, são os devires da natureza (devir-animal do homem, devir-vegetal do homem, devir-mineral do homem, devir-molecular do homem, devir-cósmico do homem... devir-Cosmo), mas também são os devires do próprio artifício (devir-máquina do homem em seu sentido mais amplo), o que, a rigor, inverte os sinais da análise operada por Heidegger: ao invés do "ser" da natureza e do "ser" do fabril dependerem do "ser" do homem para ter uma existência e um mundo, é o "vir-a-ser" (devir) do homem que depende do "vir-a-ser" (devir) da natureza e do "vir-a-ser" (devir) do artifício para ser livre em diferentes existências e mundos.

\section{CONSIDERAÇÕES FINAIS}

Ocorre que nossa pesquisa de Pós-Doutorado chega ao fim não em sua Conclusão, mas em um Apêndice, onde levantamos uma questão a respeito do pensamento de Deleuze e Guattari, a saber, será que com o personagem conceitual do esquizo no âmbito do inconsciente na obra $O$ anti-Édipo e, em seguida, com o personagem conceitual do nômade no âmbito da história na obra $\mathrm{Mil}$ Platôs, a dupla francesa não cai na armadilha do Antropocentrismo Ontológico, que ela queria não apenas contornar, mas também desarmar? Neste caso, tanto o esquizo quanto o nômade não seriam os novos sujeitos ontológicos da Filosofia, e, em particular, da Filosofia da Diferença e da Teoria das Multiplicidades, que, de algum modo, guardariam uma 
filiação relativa à família ou à linhagem de outros tantos sujeitos ontológicos, a exemplo daqueles pensados por Descartes, Kant, Husserl, Heidegger, entre outros? Ou, ao contrário, os personagens conceituais do esquizo e do nômade já não seriam mais sujeitos ontológicos, pois, ao ocupar novas paisagens, paisagens que abolem a clivagem, a separação, a fronteira entre o ontológico e o ôntico, o transcendental e o empírico, a Idéia e o sensível, já são multiplicidades em agenciamentos nos distintos platôs da imanência? Com esta pergunta não respondida, no entanto, convidamos o leitor não apenas ao exercício do pensamento, mas também à leitura de nossa pesquisa de Pós-Doutorado.

Por uma razão qualquer, a compreensão de que nada havia a esperar teve salutar efeito sobre mim. Durante semanas e meses, durante, na realidade, toda minha vida, eu vinha esperando que acontecesse algo, algum fato extrínseco que alterasse minha vida; e agora, de repente, inspirado pela absoluta desesperança de tudo, sentia-me aliviado, sentia como se tivessem arrancado um grande peso de meus ombros. Ao amanhecer, separei-me do jovem hindu, depois de lhe ter tomado alguns francos, o suficiente para um quarto. Caminhando em direção a Montparnasse, decidi deixar-me arrastar pela maré, não opor a menor resistência ao destino, fosse qual fosse a forma sob a qual se apresentasse. Nada do que me acontecera até então fora suficiente para destruir-me; nada fora destruído, exceto minhas ilusões. Eu mesmo estava intacto. O mundo estava intacto. Amanhã talvez houvesse uma revolução, uma epidemia, um terremoto; amanhã talvez não restasse uma única alma a quem se pudesse recorrer para obter simpatia, auxílio, fé. Pareceu-me que a grande calamidade já se manifestara, que eu não poderia ficar mais verdadeiramente sozinho do que naquele próprio momento. Decidi que não me apegaria a nada, que não esperaria nada, que a partir de então viveria como um animal, como uma fera carnívora, um nômade, um rapinante. Mesmo que declarassem a guerra e fosse meu destino partir, eu agarraria a baioneta e a enterraria, a enterraria até o punho. (...) Nesse próprio momento, no quieto alvorecer de um novo dia, não estava a terra tonta com crime e miséria? Algum único elemento da natureza do homem teria sido alterado, vitalmente, fundamentalmente alterado, pela incessante marcha da história? Pelo que ele chama de melhor parte de sua natureza, o homem foi traído, só isso. Nos extremos limites de seu ser espiritual o homem se encontra de novo nu como um selvagem. Quando encontra Deus, por assim dizer, ele está bem arrumado: é um esqueleto. A gente precisa afundar-se de novo na vida a fim de ganhar carne. O verbo precisa fazer-se carne; a alma tem sede. Qualquer migalha em que meus olhos pousem, agarrarei e devorarei. Se viver é a coisa suprema, então viverei, mesmo que precise tornar-me canibal. Até agora eu vinha tentando salvar meu precioso couro, preservar os poucos pedaços de carne que escondem meus ossos. Estou cheio disso. Atingi os limites da resistência. Minhas costas estão contra a parede; não posso recuar mais. No que tange à história, estou morto. Se existe algo além terei de saltar para trás. Encontrei Deus, mas ele é insuficiente. Só espiritualmente é que estou morto. Fisicamente estou vivo. Moralmente estou livre. O mundo que abandonei é uma jaula. A aurora está nascendo sobre um mundo novo, um mundo de selva no qual os espíritos descarnados rondam com garras afiadas. Se sou uma hiena, sou uma hiena descarnada e faminta: avanço para engordar-me. (MILLER, 1967, p. 85 e 86). ${ }^{6}$

\section{REFERÊNCIAS BIBLIOGRÁFICAS}

ARISTÓTELES. Metafísica. Trad. Edson Bini. SP: Edipro, 2012. Órganon. Trad. Edson Bini. SP: Edipro, 2010.

BERGSON, Henri. A evolução criadora. Trad. Bento Prado Neto. SP: Martins Fontes, 2005.

GenGrafaress

Revista do Programa de Pós-Graduação em Geografia e do Departamento de Geografia da UFES

Julho-Dezembro, 2021

ISSN 2175-370S 


\section{GEOGRAFARES}

Revista do Programa de Pós-Graduação em Geografia e do Departamento de Geografia da UFES

Julho-Dezembro, 2021

ISSN 2175-3709
. Matéria e memória: ensaio sobre a relação do corpo com o espírito. Trad. Paulo Neves. SP: Martins Fontes, 1999.

BUCHANAN, Brett. Onto-ethologies: The Animal Environments of Uexkull, Heidegger, Merleau-Ponty and Deleuze. NY: State University of New York Press, 2009.

CARDOSO JR., REBELLO, H. Entre a Natureza e Cultura: contribuição deleuziana para uma teoria empirista das relações e ontologia relacional. In: LINS, D.; OLIVEIRA, N.; BARROS, R. (Org.). Nietzsche/Deleuze: Natureza/ Cultura. SP: Lumme Editor, 2011.

DELEUZE, Gilles. A dobra: Leibniz e o barroco. Trad. Luiz B. L. Orlandi. Campinas, SP: Papirus, 1991.

. A propósito de Simondon. Trad. Luis B. L. Orlandi. In: PELBART, Peter Pál; COSTA, Rogério da (org.). O reencantamento do concreto. Cadernos de subjetividade. SP: Editora HUCITEC EDUC, 2003.

Bergsonismo. Trad. Luiz B. L. Orlandi. SP: Ed. 34, 1999.

Capitalismo e esquizofrenia. Trad. Rogério da Costa Santos. In: David Lapoujade. A ilha deserta e outros textos: Gilles Deleuze. ed.; Luiz B. L. Orlandi, org. SP: Iluminares, 2006.

Conversações. Trad. Peter Pál Pelbart. RJ: Ed. 34, 1992.

Graal, 1988

Diferença e Repetição. Trad. Luiz Orlandi e Roberto Machado. Rj:

Empirismo e subjetividade. Trad. Luiz B. L. Orlandi. SP: Ed. 34, 2012.

Lógica do sentido. Trad. Luiz Roberto Salinas Fortes. SP: Ed. Perspectiva, 1974.

O abecedário de Gilles Deleuze. Entrevista com Gilles Deleuze. Editoração: Brasil, Ministério da Educação, TV Escola, 2001. Paris: Éditions Montparnasse, 1997, VHS, 459min.

. O atual e o virtual. In: ALLIES, Éric. Deleuze Filosofia Virtual. Trad. Heloisa B.S. Rocha. SP: Ed. 34, 1996.

DELEUZE, Gilles; GUATTARI, Félix. Kafka: por uma literatura menor. Trad. Cíntia Vieira da Silva. BH: Autêntica Editora, 2015.

L'anti-Oedipe - Capitalisme et Schizophrénie 1. Paris: Minuit, 1975.

. Mil platôs - capitalismo e esquizofrenia, vol. 1. Trad. Aurélio Guerra Neto e Célia Pinto Costa. RJ: Ed. 34, 1995.

Mil platôs - capitalismo e esquizofrenia, vol. 2. Trad. Ana Lúcia de Oliveira e Lúcia Cláudia Leão. RJ: Ed. 34, 1995.

. Mil platôs - capitalismo e esquizofrenia, vol. 3. Trad. Aurélio Guerra Neto, Ana Lúcia de Oliveira, Lúcia Cláudia Leão e Suely Rolnik. SP: Ed. 34, 1996.

Mil platôs - capitalismo e esquizofrenia, vol. 4. Trad. Suely Rolnik. SP: Ed. 34, 1997. 
Mil platôs - capitalismo e esquizofrenia, vol. 5. Trad. Peter Pál

Pelbart e Janice Caiafa. SP: Ed. 34, 1997.

Mille Plateaux - Capitalismo et Schizophrénie. Paris: Minuit, 1979.

O Anti-Édipo. Trad. Luiz B. L. Orlandi. SP: Ed. 34, 2011.

O que é a filosofia? Trad. Bento Prado Jr. e Alberto Alonso Muñoz.

RJ: Ed. 34, 1992.

DESCARTES, René. Discurso do método. Trad. João Cruz Costa. RJ: Ed.

Tecnoprint, 1988 .

DUBOIS, Christian. Heidegger: Introdução a uma leitura. Trad. Bernardo Barros Coelho de Oliveira. RJ: Editora Zahar, 2004.

GUATTARI, Félix. As três ecologias. Trad. Maria Cristina F. Bittencourt. SP: Papirus, 1990.

Caosmose: um novo paradigma estético. Trad. Ana Lúcia de Oliveira e Lúcia Cláudia Leão. SP: Editora 34, 2012.

GUATTARI, Félix e ROLNIK, Suely. Micropolítica: cartografias do desejo.

Trad. Suely Rolnik. Petrópolis: Ed. Vozes, 2013.

HARDT. Michael. Gilles Deleuze: um aprendizado em filosofia. Trad. Sueli Cavendish. SP: Ed. 34, 1996.,

HEIDEGGER, Martin. Carta sobre o humanismo. Trad. Rubens Eduardo Frias. SP: Ed. Moraes, 1991.

Brasileiro, 1999.

Introdução à Metafísica. Trad. Emmanuel Carneiro Leão. RJ: Tempo O que é uma coisa? Trad. Carlos Morujão. Lisboa: Edições 70, 1987.

Os conceitos fundamentais da metafísica: mundo, finitude, solidão.

Trad. Marco Antônio Casanova. RJ: Forense Universitária, 2006.

Editora Vozes, 2001.

Ser e tempo (parte 1). Trad. Márcia de Sá Cavalcante. Petrópolis:

Ser e tempo (parte 2). Trad. Márcia de Sá Cavalcante. Petrópolis:

Editora Vozes, 2001.

Sobre a essência da verdade. Trad. Ernildo Stein. In: Os pensadores.

SP: Nova Cultural, 1991.

Sobre a essência do fundamento. Trad. Ernildo Stein. In: Os

pensadores. SP: Ed. Nova Cultural, 1991.

Cultural, 1991.

Tempo e ser. Trad. Ernildo Stein. In: Os pensadores. SP: Nova

LAPOUJADE, David. Os movimentos aberrantes. Trad. Laymert Garcia dos Santos. SP: n-1 edições, 2015.

LÉVY. Pierre. O que é o virtual? Trad. Paulo Neves. SP: Ed. 34, 1996.

MACHADO, Roberto. Deleuze e a filosofia. RJ: Graal, 1990.
Gengrafaress

Revista do Programa de Pós-Graduação em Geografia e do Departamento de Geografia da UFES

Julho-Dezembro, 2021

ISSN 2175-3709 


\section{GEOGRAFARES}

Revista do Programa de

Pós-Graduação em Geografia e do Departamento de Geografia da UFES

Julho-Dezembro, 2021

ISSN 2175-3709
MILLER, Henry. Crazy Cock. Raul de Sá Barbosa. SP: Siciliano, 1994. Trópico de câncer. Trad. Aydano Arruda. SP: IBRASA, 1967.

MODENESI, Jean Calmon. HomemTempo. RJ: UFRJ, 2009. Disponível em: $<$ www.posciencialit.letras.ufrj.br/images/Posciencialit/td/2009/10-jeancalmon_ homemtempo.pdf $>$.

PELBART, Peter Pál. Gilles, tu nous manques, mais on se débrouille. In: LINS, D. (org.). Razão Nômade. Daniel, organizador. RJ: Forense Universitária, 2005.

.. O Tempo não-reconciliado. SP: Perspectiva, 2007.

PLATÃO. Fedro. Trad. José Roberto Ferreira. Lisboa: Edições 70, 1997. Sofista. Trad. Edson Bini. SP: EDIPRO, 2007. . Timeu. Trad. Carlos Alberto Nunes. Belém: EDUFPA, 2001.

SIMONDON, Gilbert. L’individu et sa gênèse physico-biologique. Paris: Éditions Jerôme Millon, 1995.

UEXKÜLL. J. v. Dos animais e dos homens. Trad. Alberto Candeias e Anibal Garcia Pereira. Lisboa: Edição Livros do Brasil Lisboa, [19??].

ULPIANO, Claudio. Multiplicidades do eu. Transcrição a partir da palestra realizada pelo autor. RJ: Escola de artes visuais do Parque Laje, 1995.

Disponível em: <acervoclaudioulpiano.com/tag/vitalismo/>.

VATTIMO, Gianni. Introdução a Heidegger. Trad. João Gama. São Paulo: Instituto Jean Piaget, 1996.

ZANOTELLI, Cláudio Luiz. Geofilosofia e geopolítica em Mil Platôs. Vitória: EDUFES, 2014.

ZOURABICHVILI, François. Deleuze: une philosophie, Paris: PUF, 1994. O vocabulário Deleuze. Tradução: André Telles. RJ: Relume Dumará, 2004. 